SSCL-495
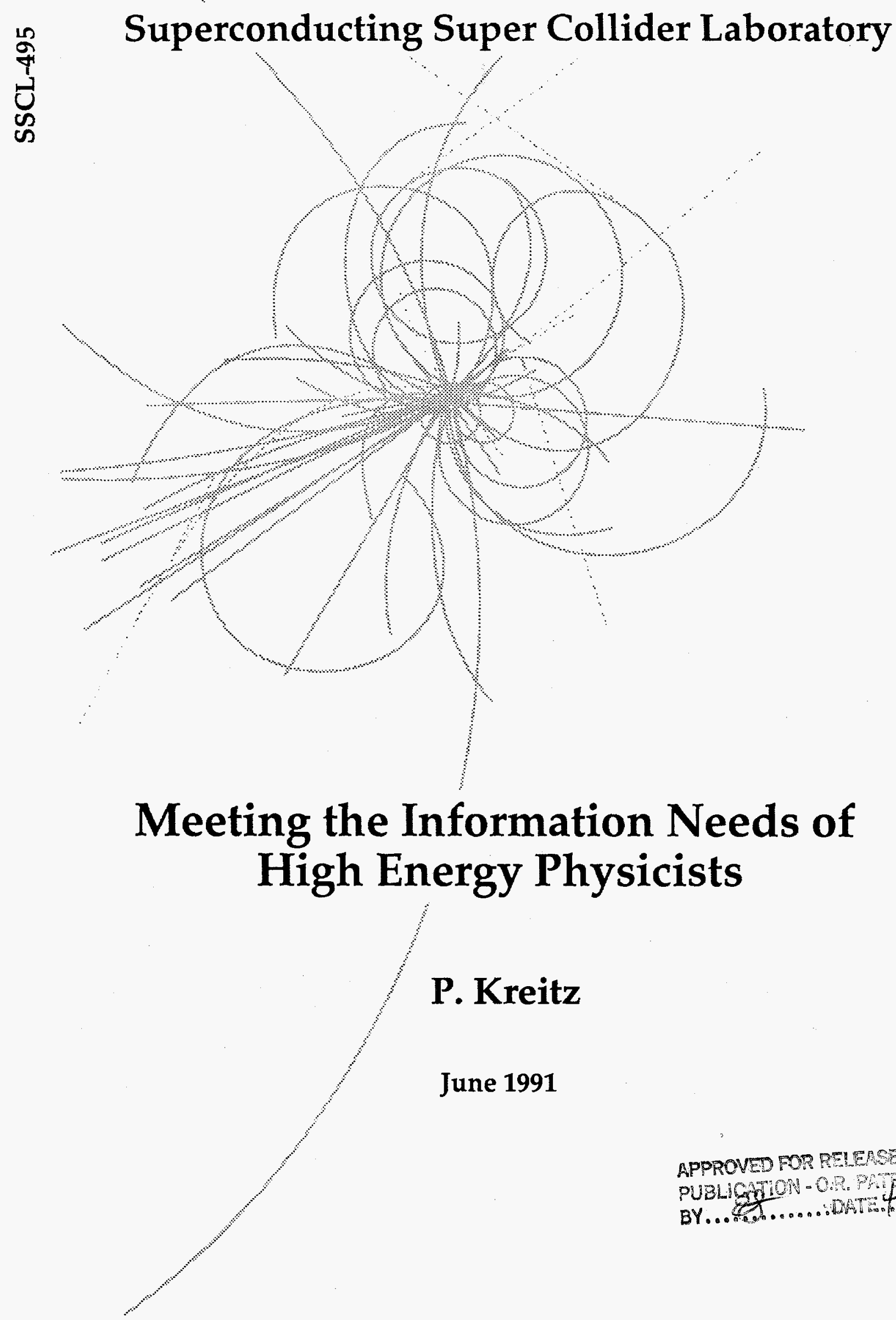

APPRONED FOR REIERSE OR

PUPLOTON-OR PAFNE GQU?

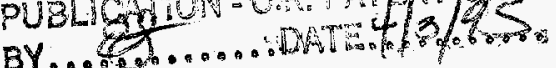




\title{
MEETING THE INFORMATION NEEDS OF HIGH ENERGY PHYSICISTS*
}

\author{
P. Kreitz \\ Library and Information Services \\ Physics Research Division \\ Superconducting Super Collider Laboratory ${ }^{\dagger}$ \\ 2550 Beckleymeade Ave. \\ Dallas, TX 75237
}

June 1991

\section{DISCLAIMER}

\begin{abstract}
This report was prepared as an account of work sponsored by an agency of the United States Government. Neither the United States Government nor any agency thereof, nor any of their employees, makes any warranty, express or implied, or assumes any legal liability or responsibility for the accuracy, completeness, or usefulness of any information, apparatus, product, or process disclosed, or represents that its use would not infringe privately owned rights. Reference herein to any specific commercial product, process, or service by trade name, trademark, manufacturer, or otherwise does not necessarily constitute or imply its endorsement, recommendation, or favoring by the United States Government or any agency thereof. The views and opinions of authors expressed herein do not necessarily state or reflect those of the United States Government or any agency thereof.
\end{abstract}

*To be published in Library Administration and Management, June 1991.

fOperated by the Universities Research Association, Inc., for the U.S. Department of Energy under Contract No. DE-AC02-89ER40486. 


\section{DISCLAIMER}

Portions of this document may be illegible in electronic image products. Images are produced from the best available original document. 


\title{
MEETING THE INFORMATION NEEDS OF HIGH ENERGY PHYSICISTS*
}

\author{
Patricia Kreitz \\ Library and Information Services \\ Physics Research Division \\ Superconducting Super Collider Laboratory ${ }^{\dagger}$ \\ 2550 Beckleymeade Ave. \\ Dallas, TX 75237
}

\begin{abstract}
"You mean interlibrary loan takes four hours? Why such a delay?"
"Can you give me the names and addresses of all the historically black colleges in the U.S.? I'll hold while you get it."

"I've just been told to write the safety and quality assurance manuals for $\mathrm{X}$ and $\mathrm{Z}$ sites by the end of the week. My boss said the Library would help."

"Can you give me the citation to this line of poetry? I need it for a presentation in ten minutes."

"Please find out everything you can about "CRMA Gb/s Lan/Man" and get me anything written on it by the end of the week."

"I need a literature search on chaos in physics-can you send the full text of any articles found to my computer this moming?"
\end{abstract}

Information on any subject-delivered on demand. For most library patrons, this sentence would describe their ideal library. As the above examples of reference questions show, that desire to have instant access to information is not just an ideal goal to be reached someday-but a daily and often hourly requirement at the Superconducting Super Collider Laboratory (SSCL) Library. In the specialized field of high energy physics, that ideal is evolving into reality much faster than in other fields. Libraries serving clientele in this arena must aggressively redefine their role in order to serve users who otherwise must and will take information management into their own hands, a task for which they are not trained. It is perhaps appropriate that the project building the world's largest and most powerful particle accelerator provides an environment in which changes-and challenges-in information access, control and organization are rapidly accelerating the redefinition of librarianship as a profession.

The Superconducting Super Collider, an underground particle accelerator 54 miles in circumference, being built south of Dallas, Texas, will be the United States' largest scientific project and the world's most powerful microscope. When completed by physicists, engineers and computer scientists, this machine will enable scientists to explore fundamental questions about the nature of matter and energy through its ability to replicate and analyze physical events that took place in the universe's first microsecond of existence. A substantial amount of the technology needed to build and operate the accelerator has not been developed yet-and so the physicists, engineers, computer scientists, designers, administrators and support staff need cutting-edge research material as well as easy access to existing data. Because this is a highly visible

\footnotetext{
*To be published in Library Administration and Management, June 1991.

†Operated by the Universities Research Association, Inc., for the U.S. Department of Energy under Contract No. DE-AC02-89ER40486.
} 
big-science effort and is a priority of the Bush Administration, it receives a large amount of publicity and rigorous fiscal and administrative scrutiny by the Department of Energy. Congress and other oversight groups. Staff at the Laboratory are under tremendous pressure to meet milestones, keep budgets tight and complete the accelerator and its detectors by the year 2000 . This pressure combined with the fact that many systems and components are still in the design phase, results in a high volume of reference questions with incredibly short deadlines.

This high-pressure research environment is a challenge. Such challenges are often faced by special librarians or academic librarians serving faculty with grant or publication deadlines. There is nothing in such an environment which would inherently devalue the librarian's role-in fact it may be more valued if information becomes critical to research or project success. However at the SSCL, the intense pressure to meet deadlines is coupled with several unique circumstances which are compelling the Library -in order to retain a meaningful role in information management - beyond state-of-the-art toward a radical redefinition of the information professional and of information "service." These special circumstances include the nature of high energy physics research, the structure of its literature, the sophisticated level of computer use in physics environments, and the high value physicists place on access to information.

High energy physics research in this century is the province of rigorously trained and imaginative individuals who have, along with their scientific skills, developed the ability to plan and execute internationally cooperative projects demanding long lead times. Fundamental physics requires increasingly larger, more complex and more costly experimental machinery and increasingly larger working groups of scientists whose areas of expertise are becoming more specialized. In order to design and build new particle accelerators (the "microscopes" of the high energy physicist) and the detectors that operate within them (the "lens" of the microscope), physicists have had to cooperate across intemational boundaries-perhaps more so than in any other scientific field. These machines, and the large collaborations that work on them, have also increased the scale of financial support required-and thus the scale of planning needed.

The international scope and high degree of collaboration in high energy physics is reflected in the type of literature it produces and in the structure of its bibliography. Preprints-written for submission to joumals and distributed in advance of publication-are an important format for disseminating research in this field. Preprints are officially disseminated by the researchers to libraries, other institutions and individuals. However, preprints lack the cataloging and indexing given to materials in formal journals. They also lack the wide access, making it difficult to find work which has only appeared in preprint form, especially if it is a few years old. Therefore, in keeping with the cooperative nature of the science they serve, the world's major accelerator sites collaborate to contribute bibliographic data to the SPIRES databases of high energy physics literature created and maintained by the Stanford Linear Accelerator Center Library. This resource provides online access worldwide to bibliographic information not only about preprints, but also about joumal articles, books, and conference proceedings on subjects of interest to the high energy physics community. Although preprints are often individually distributed, physicists worldwide rely on SPIRES to alert them to the preprint literature their personal distribution systems have missed. Coupled with several other commercially available databases such as SPIN, INSPEC and PHYS, these resounces constitute an organized, timely and accessible bibliography of the literature in this field.

Not only are high energy physicists able to think on a large scale in long time frames and to benefit from a well-organized body of research results, but they are also extremely computer literate. Among many researchers at the SSCL, worldwide electronic mail is used as frequently as the telephone as a means of scholarly communication. Their expertise and resources do not stop with e-mail, since physicists traditionally have enormous amounts of computer power at their fingertips. This computational power is used to design accelerators and detectors and then to record and analyze the results of experiments. To researchers who have extensive experience in the capture, storage and analysis of massive amounts of data, electronic access to and delivery of information seems both straightforward and inevitable. 
Traditionally, high energy physicists are strong supporters of libraries and value the role librarians play in controlling and providing access to published and preprint literature. Physicists are also unique among scientists for their reliance on libraries to provide copies of journal literature. ${ }^{1}$ Cooperative efforts such as the SPIRES databases attest to the value physicists place on information management. This value is often expressed. In the first few months of the SSCL's existence, physicists collaborating on the design of the accelerator and the detectors declared that they would hold their meetings at other sites until a library adequate to support their work existed at the SSCL. On another occasion, physicists at the SSCL wanted to trim all overhead budgets except the Library's. In return for this support, they expect fast, quality service. In this demanding environment, the Library must stay in the forefront of electronic information management.

As can be seen from the above description, physicists take an active and cooperative role in planning to meet their future research needs and they are very comfortable with computer access and electronic environments. Recently, their planning efforts have turned to examining ways to better meet their information needs. The American Physical Society's Task Force on Electronic Information Systems ${ }^{2}$ recently proposed a world scientific information system that would completely integrate the production, diffusion, and retrieval of scientific documents over high speed networks by the year 2020 . For the most part, the report outlined broadly the steps that need to be taken if this goal is to be achieved. However, it was quite specific when describing one of the middle-range goals_-"a National Physics Database, projected as the heart of a worldwide Physics Information System and containing (among other things) books, papers conference abstracts and proceedings, numerical data, and computer programs, all searchable at one time."3 There was no library professional on this task force, and the report does not specifically include library involvement in the creation or maintenance of the database. When discussing how the Physics Information System could be administratively organized, the report mentions the creation of a National Library of Science as one possibility.

Left on their own high energy physicists have the motive, method and opportunity to pursue this vision of physics information access in the year 2020. However, physics librarians at the SSCL and at other laboratories are already engaged in planning and projects that will enable them to take a central role in making this vision a reality. A role that builds on the profession's unique strengths in the information field - knowledge of access systems, of patron information needs and search behavior, and of collection development (which in the new electronic millennium ought to be called resource identification). Currently, four high energy physics libraries, one of which is the SSCL, are in the discussion stages of a cooperative effort to develop full-text access to the preprints in SPIRES. This project will probably take five years but will allow users of SPIRES to do full text searching and then display the entire preprint online. Locally the SSCL Library has started developing a Lab-wide information access system which will connect the searcher with all intemal information resources and a variety of external ones as seamlessly as possible. This "virtual library" will provide access not only to traditional citations but also to full text, raw data, images and sound. It will have sophisticated subject control as well as natural language retrieval and will eventually weigh the relevance of retrieved information according to the user's pre-established interest profile and run automatic SDI's against that profile. Achieving this goal of a Lab-wide information access system requires political skill, professional competence and an unshakeable belief that librarians are uniquely qualified to organize information and help users access it. This system will meet the Laboratory's need for high speed, efficient information delivery. It will also serve as a model, on a reduced scale, of the American Physical Society's vision of a worldwide, totally integrated library able to provide full-text delivery directly to the physicist's desktop.

Just as the Superconducting Super Collider Laboratory will stretch the frontiers of our knowledge of the physical world - so the challenge of meeting the information needs of the people working on this high energy physics project is stretching the definition of "library" beyond the traditional academic or special library roles. It is moving us rapidly into the arena of world-wide electronic information management. 


\section{REFERENCES}

1. Donald W. King and Nancy K. Roderer, "Communication in Physics - the Use of Joumals," Physics Today 35:44 (Oct. 1982).

2. "Report of the APS Task Force on Electronic Information Systems," Bulletin of the American Physical Society 36:1119-1153 (Apr. 1991).

3. News of the APS, "Task Force Report Looks at Future of Information Services," Bulletin of the American Physical Society 36:1106 (Apr. 1991). 